MSC 35Q93, 49J20

DOI: $10.14529 /$ jcem 150305

\title{
ALGORITHM FOR NUMERICAL METHOD OF SOLUTION OF THE OPTIMAL CONTROL PROBLEM FOR SEMILINEAR SOBOLEV TYPE MODELS ON BASIS OF DECOMPOSITION METHOD
}

\author{
N.A. Manakova, South Ural State University, Chelyabinsk, Russian Federation, \\ manakovana@susu.ac.ru
}

The question of finding the numerical solutions of optimal control problems in mathematical models based on the degenerate semilinear equations of mathematical physics is one of the most important. It is so because of a large number of applications of such problems. In the case of non-linear state equation the search for the numerical solution of optimal control problem becomes more difficult. A lot of initial-boundary value problems for the equations and the systems of equations which are not resolved with respect to time derivative are considered in the framework of abstract Sobolev type equations that make up the vast field of non-classical equations of mathematical physics. We are interested in the optimal control problem to solutions of the Showalter - Sidorov problem for the semilinear Sobolev type equation. The article proposes to use a decomposition method, allowing to linearize a non-linear equation, and the penalty method, which allows to find an approximate solution of the problem. Our numerical method is based on the Galerkin method, and the method of decomposition. Using it we find approximate solutions of optimal control problem for the Hoff mathematical model and the generalized mathematical model of deformation of the structure of I-beams.

Keywords: the Sobolev type equation; optimal control; the Showalter - Sidorov problem; the Galerkin method; decomposition method.

\section{Introduction}

The need for constructing and examination of mathematical models is growing due to the high rate of production and technology. The possibility of studying the process using a mathematical modelling is quite relevant because the conducting of natural experiments is expensive. A large class of mathematical models is based on non-classical semilinear partial differential equations that are not solved for the derivative of time. Now equations, which are not solved for the time derivative, are called the Sobolev-type equations. This tradition takes place in the native works [1-6], and the foreign ones, e.g., [7]. As a rule, the processes in mechanics, engineering and manufacturing are controllable. The study of external influence on the studied process, using which it is possible to achieve the desired result, plays a special role.

Consider optimal control

$$
J(x, u) \rightarrow \min
$$

by solutions of the Showalter - Sidorov problem

$$
L\left(x(0)-x_{0}\right)=0
$$

for the semilinear Sobolev type equation

$$
L \dot{x}+\sum_{j=1}^{k} N_{j}(x)=u \text {. }
$$


Here $J(x, u)$ is some specially constructed quality functional; the control $u \in \mathfrak{U}_{a d}$, where $\mathfrak{U}_{a d}$ is some closed convex set in the space of controls, which is denoted $\mathfrak{U}$. Linear optimal control problem for the Sobolev type equation with initial Cauchy condition was first posed and studied by G.A. Sviridyuk and A.A. Efremov [8]. The work [9] is dedicated to the study of optimal control problems for the linear Sobolev type equations with initial-final condition. The study of optimal control problems for the Sobolev type equations of high order was begun in [10]. Recently there were applications of optimal control problems for the Leontief type systems $[11,12]$ to the problems of dynamic measurements, see $[13,14]$.

In [15] it is shown that condition (2) for equation (3) is more natural and allows to avoid difficulties associated with the study of the Cauchy problem. The Showalter - Sidorov condition is a direct generalization of the Cauchy condition. The initial-final condition is more general initial condition for the linear Sobolev type equations than condition (2), see [16]. The application of the Showalter - Sidorov condition (2) led to a simplification of numerical studies of the Leontief type systems [11], and its optimal control problems [12].

The using of the decomposition method for finding the numerical solution of optimal control problem was proposed in the monograph [17]. This method allows to linearize the state equation and to transfer the whole phenomenon of non-linearity to the functional. Research and construction of numerical methods for solving optimal control problems come to the fore due to the development of modern computing technology. The work [11] is devoted to the constructing of algorithm of numerical solution of linear optimal control problems. Obtaining of analytical solution or distribution of existing approaches for finding numerical solutions of optimal control problems in nonlinear degenerate model is not always possible. The numerical method based on the Galerkin method and the method of decomposition is constructed in the paper. Using our method one can find approximate solutions of the optimal control problem (1) - (3). On the basis of this method we find approximate solutions of optimal control problem for the Hoff mathematical model [18] and the generalized mathematical model of deformation of the structure of the I-beams [19].

\section{Optimal Control Problem}

Let $\mathcal{H}=(\mathcal{H} ;\langle\cdot, \cdot\rangle)$ be a real separable Hilbert space identified with its dual. Let $\left(\mathfrak{H}^{\prime}, \mathfrak{H}^{*}\right)$ and $\left(\mathfrak{B}_{j}, \mathfrak{B}_{j}^{*}\right), j=\overline{1, k}, k \in \mathbb{N}$ be dual (with respect to the duality $\langle\cdot, \cdot\rangle$ ) pairs of reflexive Banach spaces, moreover, let the embeddings

$$
\mathfrak{H} \hookrightarrow \mathfrak{B}_{k} \hookrightarrow \ldots \hookrightarrow \mathfrak{B}_{1} \hookrightarrow \mathcal{H} \hookrightarrow \mathfrak{B}_{1}^{*} \hookrightarrow \ldots \hookrightarrow \mathfrak{B}_{k}^{*} \hookrightarrow \mathfrak{H}^{*}
$$

be dense and continuous, and enclosure

$$
\mathfrak{H} \Subset \mathcal{H}
$$

be compact. Let $L \in \mathcal{L}\left(\mathfrak{H} ; \mathfrak{H}^{*}\right)$ be a linear self-adjoint positive semidefinite Fredholm operator orthonormal (in the sense of $\mathcal{H}$ ), set $\left\{\varphi_{k}\right\}$ of eigenvectors be a basis in the space $\mathcal{H}$. In further, let $N_{j} \in C^{r}\left(\mathfrak{B}_{j} ; \mathfrak{B}_{j}^{*}\right), j=1, \ldots k$, be an $s$-monotone operators (i.e. $\left.\left\langle N_{j y}^{\prime} x, x\right\rangle>0, \forall x, y \in \mathfrak{B}_{j} \backslash\{0\}\right)$ and a $p_{j}$-coercive operator (i.e. $\left\langle N_{j}(x), x\right\rangle \geq C_{N}\|x\|^{p_{j}}$ and $\left\|N_{j}(x)\right\|_{*} \leq C^{N}\|x\|^{p_{j}-1}$ for some constants $C_{N}, C^{N} \in \mathbb{R}_{+}$and $p_{j} \in[2,+\infty)$ and for any $x \in \mathfrak{B}_{j}$, where $\|\cdot\|,\|\cdot\|_{*}$ are the norms in the spaces $\mathfrak{B}_{j}$ and $\mathfrak{B}_{j}^{*}$, respectively), where $p_{k}=\max _{j} p_{j}$. For smooth operator $N_{j}: \mathfrak{B}_{j} \rightarrow \mathfrak{B}_{j}^{*}$, strong monotonicity implies $s$-monotonicity, and $s$-monotonicity implies strict monotonicity [20]. 
Consider the Showalter - Sidorov problem (2) for the semilinear Sobolev type equation (3). Let $T \in \mathbb{R}_{+}$. Consider the space $\mathfrak{U}=L_{q_{k}}\left(0, T ; \mathfrak{B}_{k}^{*}\right), p_{k}^{-1}+q_{k}^{-1}=1$, and define a closed convex set $\mathfrak{U}_{a d} \subset \mathfrak{U}$. Consider the optimal control problem (1) by the solutions of problem (2), (3), where cost functional is given as

$$
J(x, u)=\beta \int_{0}^{T}\left\|x(t)-z_{d}(t)\right\|_{\mathfrak{B}_{k}}^{p_{k}} d t+(1-\beta) \int_{0}^{T}\|u(t)\|_{\mathfrak{H}}^{2} d t, \beta \in(0,1),
$$

where $z_{d}=z_{d}(t)$ - wishful state of the system, which we need to achieve using the control. Consider the space

$$
\mathfrak{X}=\left\{x \mid x \in L_{\infty}(0, T ; \operatorname{coim} L) \cap L_{p_{k}}\left(0, T ; \mathfrak{B}_{k}\right), \frac{d x}{d t} \in L_{2}(0, T ; \mathfrak{H})\right\} .
$$

Definition 1. A pair $(\tilde{x}, \tilde{u}) \in \mathfrak{X} \times \mathfrak{U}_{a d}$ is called a solution of problem (1) - (3), if

$$
J(\tilde{x}, \tilde{u})=\inf _{(x, u)} J(x, u)
$$

and every $(x, u)$ satisfies (2), (3), and vector $\tilde{u}$ is called an optimal control.

Theorem 1. [18] For an arbitrary $x_{0} \in \mathfrak{H}, T \in \mathbb{R}_{+}$there exists solution of problem (1) - (3).

In monograph [17] it was proposed to use the decomposition method to find numerical solution of the optimal control problem. This method allows to linearize the state equation and to extend a phenomenon of nonlinearity to the functional. Let us linearize the equation in (3) using an additional variable in the state equation. To this end let $x=x(u, v)=$ $x(t, u, v)$ be a solution of linear problem with respect to vector-function $x$

$$
L \dot{x}+\sum_{j=1}^{k} N_{j}(v)=u, \quad x(u, v)=v, \quad L\left(x(0)-x_{0}\right)=0, u \in \mathfrak{U}_{a d}, v \in L_{p_{k}}\left(0, T ; \mathfrak{B}_{k}\right) .
$$

Therefore the optimal control problem (1) - (3) with the penalty functional (4) is equivalent to the problem (1), (5) with the functional

$$
\begin{aligned}
& J_{\theta}(x, u, v)=\theta \cdot \beta \int_{0}^{T}\left\|x(t)-z_{d}(t)\right\|_{\mathfrak{B}_{k}}^{p_{k}} d t+ \\
& +(1-\theta) \cdot \beta \int_{0}^{T}\left\|v(t)-z_{d}(t)\right\|_{\mathfrak{B}_{k}}^{p_{k}} d t+(1-\beta) \int_{0}^{T}\|u(t)\|_{\mathfrak{H}^{*}}^{2} d t, \theta \in(0,1) .
\end{aligned}
$$

Theorem 2. [21] For any $x_{0} \in \mathfrak{H}, T \in \mathbb{R}_{+}$there exists the solution of optimal control problem (1), (5).

Consider the problem of finding an approximate solution of problem (1), (5). To this end we use the penalty method [17] and consider the system of states

$$
L \dot{x}+\sum_{j=1}^{k} N_{j}(v)=u, \quad L\left(x(0)-x_{0}\right)=0, u \in \mathfrak{U}_{a d}, v \in L_{p_{k}}\left(0, T ; \mathfrak{B}_{k}\right)
$$


and the optimal control problem

$$
J_{\theta}^{\varepsilon}(x, u, v) \rightarrow \min
$$

with the penalty functional in the following form:

$$
\begin{aligned}
J_{\theta}^{\varepsilon}(x, v, u)= & \theta \cdot \beta \int_{0}^{T}\left\|x(t)-z_{d}(t)\right\|_{\mathfrak{B}_{k}}^{p_{k}} d t+(1-\theta) \cdot \beta \int_{0}^{T}\left\|v(t)-z_{d}(t)\right\|_{\mathfrak{B}_{k}}^{p_{k}} d t+ \\
& +(1-\beta) \int_{0}^{T}\|u(t)\|_{\mathfrak{B}_{k}^{*}}^{2} d t+r_{\varepsilon} \int_{0}^{T}\|x(t, v, u)-v(t)\|_{\mathcal{H}}^{2} d t .
\end{aligned}
$$

where $(x, v, u)$ - is a solution of the problem (7), and $r_{\varepsilon} \rightarrow 0+$ is a parameter of fine.

Theorem 3. [21] For any $x_{0} \in \mathfrak{H}, T \in \mathbb{R}_{+}, \varepsilon>0$ there exists the solution $\left(x_{\varepsilon}, v_{\varepsilon}, u_{\varepsilon}\right)$ of the problem (7), (8).

Theorem 4. [21] For any $x_{0} \in \mathfrak{H}, T \in \mathbb{R}_{+}$and when $\varepsilon \rightarrow 0+$ there exists the sequence $\left\{v_{\varepsilon}, u_{\varepsilon}\right\}$ such that

$$
v_{\varepsilon} \rightarrow \tilde{v}, \quad u_{\varepsilon} \rightarrow \tilde{u}
$$

where the pair $(\tilde{v}, \tilde{u})=(\tilde{x}, \tilde{u})-$ solution of the problem (1) - (3).

\section{Algorithm for the Numerical Method}

We are interested in the process of the control of solutions of the Showalter - Sidorov problem (2), (3). Our goal is to find the approximate solution of optimal control problem (1) by the solutions of problem (2), (3), where cost functional is given as (4). Let us describe the algorithm for the numerical solution of the problem (1) - (3). This algorithm is based on the modified Galerkin - Petrov method and the Ritz method.

Let $\sigma(L)$ be spectrum of the operator $L$. Because of the properties of the operator $L$, its spectrum $\sigma(L)$ is non-negative, discrete, finite multiplicity and thickens only to $+\infty$. Let $\left\{\lambda_{i}\right\}$ be the set of the eigenvalues, which are numbered in non-decreasing according to multiplicity. Let $\left\{\varphi_{i}\right\}$ be the set of the corresponding eigenfunctions which are orthonormal with respect to the scalar product $\langle\cdot, \cdot\rangle$ from $\mathcal{H}$. They form an orthonormal basis in the space $\mathcal{H}$.

Let us find an approximate solution $\tilde{x}(s, t)$ of problem $(2),(3)$ as the sum

$$
\tilde{x}(s, t)=x^{m}(s, t)=\sum_{i=1}^{m} a_{i}(t) \varphi_{i}(s),
$$

where $m \in \mathbb{N}, m>l, l=\operatorname{dim} \operatorname{ker} L$ (to take into account the effects of the reduced equation).

We represent the right side of equation (3) as

$$
\tilde{u}(s, t)=\sum_{i=1}^{m}<u(s, t), \varphi_{i}(s)>\varphi_{i}(s)=\sum_{i=1}^{m} u_{i}(t) \varphi_{i}(s) .
$$


We substitute Galerkin sums (10) and (11) to equation (3). So we get a system of nonlinear differential equations

$$
\left\langle L x_{t}^{m}, \varphi_{i}\right\rangle+\left\langle\sum_{j=1}^{k} N_{j}\left(x^{m}\right), \varphi_{i}\right\rangle=\left\langle u, \varphi_{i}\right\rangle, i=1, \ldots, m .
$$

Here, depending on the parameter $\lambda$, the equations of this system can be differential or algebraic. Because of nonlinearity of the equations, we can not obviously obtain the dependence $a_{j}(t)$ from $a_{i}(t), i=1, \ldots, m, i \neq j$ and $u_{i}(t), i=1, \ldots, m$. In contradiction to the linear case, this does not allow us to solve the problem of finding the functional minimum with respect to $u_{i}(t), i=1, \ldots, m$. Therefore before performing of consecutive approximations of the Galerkin - Petrov method we do the following. First we decompose equation (2) such that to linearize this equation. After that we introduce the penalty functional, which allows to find an approximate solution of the original problem. To this end we introduce in equation (3) an unknown function $v(s, t)$ such that

$$
L \dot{x}+\sum_{j=1}^{k} N_{j}(v)=u, x(s, t)=v(s, t)
$$

The equations in (13) are linear with respect to the function $x(s, t)$. By the second equality in (13), the penalty functional (4) is equivalent to the functional (6). By the theorem 2, the solution of problem (1) - (3) with penalty functional (4) is equivalent to the solution of problem (1), (2), (13) with penalty functional (6).

To find the required approximate solution we use the penalty method. Let the penalty functional be in the form (9). Then our problem reduces to finding triples of minimizing functions $(x, v, u)$. Represent $\tilde{v}(s, t)$ as a sum

$$
\tilde{v}(s, t)=v^{m}(s, t)=\sum_{i=1}^{m} v_{i}(t) \varphi_{i}(s) .
$$

Substitute Galerkin sums (10), (11), (14) in equation (13). We get the differential equation

$$
L \dot{\tilde{x}}+\sum_{j=1}^{k} N_{j}(\tilde{v})=\tilde{u} .
$$

Then, scalar in $\mathcal{H}$ we multiply resulting equation (15) on the eigenfunctions $\varphi_{i}(s), i=$ $1, \ldots, m$, and we get the system of the equations

$$
\left\langle L x_{t}^{m}, \varphi_{i}\right\rangle+\left\langle\sum_{j=1}^{k} N_{j}\left(v^{m}\right), \varphi_{i}\right\rangle=\left\langle u^{m}, \varphi_{i}\right\rangle
$$

$i=1, \ldots, m$.

Depending on the parameter $\lambda$, equations of system (16) can be differential or algebraic. Consider these cases.

(i) Let $\lambda \notin \sigma(L)$. In this case all equations of system (16) are ordinary differential equations of the first order. To solve this system with respect to $a_{i}(t), i=1, \ldots, m$, we find $m$ initial conditions in the following way. Scalar in $\mathcal{H}$ we multiply conditions (2) 
on eigenfunctions $\varphi_{i}(s), i=1, \ldots, m$. After that we solve thus obtained system of linear first order differential equations with initial conditions and express unknown function coefficients $a_{j}(t), j=1, \ldots, m$ in the approximate solution $\tilde{x}(s, t)=x^{m}(s, t)$ through $a_{i}(t), i=1, \ldots, m, i \neq j, v_{i}(t), i=1, \ldots, m, u_{i}(t), i=1, \ldots, m$.

(ii) Let $\lambda \in \sigma(L)$, where $l$ - the multiplicity of the first eigenvalue $L$. In this case the equations of system (16) with numbers $1_{1}, \ldots, 1_{l}$ are algebraic, and the rest ones differential. Consider the systems of the first order differential equations and the algebraic equations. To solve the system of algebraic-differential equations with respect to $a_{i}(t), i=$ $1, \ldots, m$, we find $m-l$ initial conditions from the Showalter - Sidorov condition (2). The solution of the algebraic-differential system exists for any initial functions. We exclude the initial conditions corresponding to $a_{1_{j}}(0), j=1, \ldots, l$ and solve the algebraic-differential system. After that the unknown function coefficients $a_{i}(t), i=1, \ldots, m$ are expressed in the approximate solution $\tilde{x}(s, t)=x^{m}(s, t)$ through $v_{i}(t), i=1, \ldots, m, u_{i}(t), i=1, \ldots, m$.

(iii) Let us find the minimum of the functional. To this end we substitute the obtaining representation for $\tilde{x}(s, t)=x^{m}(s, t)$ and (11), (14) to functional (9). After that, using the Ritz method, we find unknown values $v_{i}(t), i=1, \ldots, m, u_{i}(t), i=r, \ldots, m$ in the form

$$
v_{i}(t, N)=\sum_{n=1}^{N} b_{n} \sin \left(\frac{\pi n t}{l}\right), u_{i}(t, N)=\sum_{n=1}^{N} c_{n} \sin \left(\frac{\pi n t}{l}\right)
$$

or

$$
v_{i}(t, N)=\sum_{n=0}^{N} b_{n} t^{n}, u_{i}(t, N)=\sum_{n=0}^{N} c_{n} t^{n}
$$

Note that we choose the coefficients $b_{n}$ and $c_{n}$ such that the functions $v_{i}(t, N), u_{i}(t, N)$ minimizes functional (9). Therefore, the problem is reduced to finding the extremum of function of $2(N+1) \times m(2 N \times m)$ variables.

An algorithm of finding the approximate solution of problem (1) - (3) is reduced to six steps.

Step 1. To find eigenvalues and eigenfunctions of the operator $L$, that is, the solution of the problem

$$
<L \varphi, v>=\lambda<\varphi, v>
$$

with appropriate boundary conditions.

Step 2. To find the number $m$ such that from $m$ we can calculate the approximate solution using the condition: $m>l, l=\operatorname{dim} \operatorname{ker} L$.

Step 3. To check by specified parameter $\lambda$ : mathematical model corresponds to degenerate case or to non-degenerate one.

Step 4. To express $a_{i}(t), i=1, \ldots, m$ in the approximate solution $\tilde{x}(s, t)=x^{m}(s, t)$ through $v_{i}(t), i=1, \ldots, m, u_{i}(t), i=1, \ldots, m$, using the specified initial functions, depending on cases (i), (ii).

Step 5. To represent the unknown functions $v_{i}(t), i=1, \ldots, m, u_{i}(t), i=1, \ldots, m$ using (17) or (18) in penalty functional (9).

Step 6. To find the minimum of a functional and functions $\tilde{x}(s, t), \tilde{v}(s, t), \tilde{u}(s, t)$.

\section{Computational Experiments}

We are interested in the process of control of the behavior of the I-beam [18], which is under constant load. In a cylinder $Q_{T}=(0, l) \times(0, T), T>0$ consider the Dirichlet 
condition

$$
x(s, t)=0,(s, t) \in(0, l) \times(0, T)
$$

and the Showalter - Sidorov condition

$$
(\lambda+\Delta)\left(x(s, 0)-x_{0}(s)\right)=0, s \in(0, l)
$$

for the generalized Hoff equation

$$
(-\lambda-\Delta) x_{t}+\alpha x+\alpha_{1} x^{3}+\alpha_{2} x^{5}+\ldots+\alpha_{k-1} x^{2 k-1}+\alpha_{k} x^{2 k+1}=u
$$

where function $u=u(s, t)$ describes the impact of the external manager (side loading), and operator $\Delta=\frac{\partial^{2}}{s^{2}}$. Our goal is to find an approximate solution of the optimal control problem

$$
J(x, u) \rightarrow \min
$$

by the solutions of problem (19) - (21), where cost functional is in the form

$$
J(x, u)=\beta \int_{0}^{T} \int_{0}^{l}\left|x(s, t)-z_{d}(s, t)\right|^{2 k+2} d s d t+(1-\beta) \int_{0}^{T} \int_{0}^{l}|u|^{2} d s d t .
$$

The algorithm for finding an approximate solution of problem (19) - (21) using decomposition, penalty, Galerkin - Petrov methods was described in 2. By the proposed method, in a cylinder $Q_{T}$ we consider Dirichlet condition (19) and Showalter - Sidorov condition (20) for the equation

$$
(-\lambda-\Delta) x_{t}+\alpha x+\alpha_{1} v^{3}+\alpha_{2} v^{5}+\ldots+\alpha_{k-1} v^{2 k-1}+\alpha_{k} v^{2 k+1}=u \text {. }
$$

Equation $(24)$ is linear with respect to the function $x(s, t)$. We define a penalty functional as

$$
\begin{gathered}
J_{\theta}^{\varepsilon}(x, v, u)=\beta \theta \int_{0}^{T} \int_{0}^{l}\left|x(s, t)-z_{d}(s, t)\right|^{2 k+2} d s d t+ \\
\beta(1-\theta) \int_{0}^{T} \int_{0}^{l}\left|v(s, t)-z_{d}(s, t)\right|^{2 k+2} d s d t+ \\
+(1-\beta) \int_{0}^{T} \int_{0}^{l}|u|^{2} d s d t+\frac{1}{\varepsilon} \int_{0}^{T} \int_{0}^{l}|x-v|^{2} d s d t .
\end{gathered}
$$

Example 1. Consider problem (19) - (22) in the case $\lambda=1, \alpha=1, \alpha_{1}=2, l=\pi, T=$ $1, \theta=\frac{1}{2}, \beta=\frac{99}{100}, \varepsilon=\frac{1}{10}, x_{0}(s)=\sqrt{\frac{2}{\pi}}(\sin s+2 \sin (2 s)+2 \sin (3 s)), z_{d}(s, t)=\sqrt{\frac{2}{\pi}}(\sin s+$ $\left.(t+2) \sin (2 s)+\left(t^{2}+2\right) \sin (3 s)\right), m=3, N=3$. Graphs of the functions $x_{0}(s), z_{d}(s, t)$ are shown in Fig. 1.

The results of the calculations are the coefficients of the control (see. Table 1), such that the value of the functional $J=4,098527$. An approximate solution of the problem 


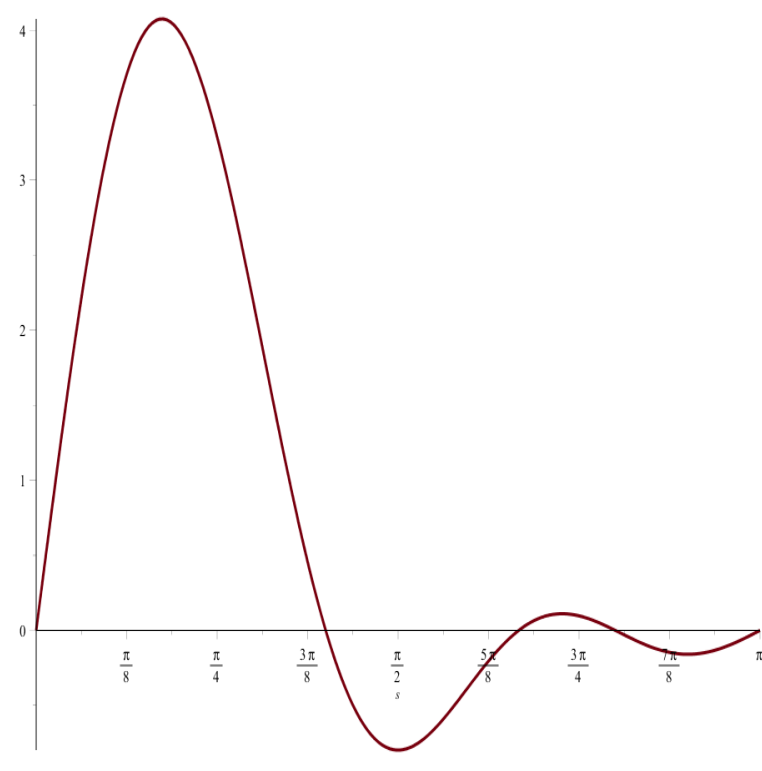

a)

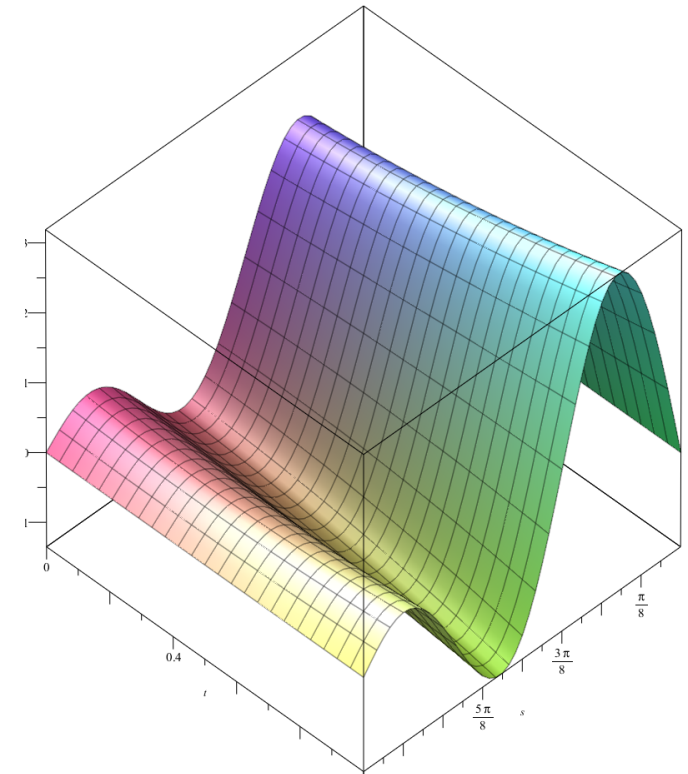

b)

Fig. 1. The initial functions of problem (19) - (22):

a) function $x_{0}(s)$; b) function $z_{d}(s, t)$

Table 1

\begin{tabular}{|l|l|l|l|}
\hline$b_{10}=3,78551$ & $b_{11}=0,191363$ & $b_{12}=0,332450$ & $b_{13}=0,014591$ \\
\hline$b_{20}=9,54792$ & $b_{21}=-5,66737$ & $b_{22}=13,4783$ & $b_{23}=-10,5349$ \\
\hline$b_{30}=-0,125106$ & $b_{31}=6,52025$ & $b_{32}=1,12257$ & $b_{33}=-7,21200$ \\
\hline$c_{10}=0,232990$ & $c_{11}=-0,020644$ & $c_{12}=0,051504$ & $c_{13}=0,000723$ \\
\hline$c_{20}=0,941092$ & $c_{21}=0,780535$ & $c_{22}=-0,235198$ & $c_{23}=-0,000466$ \\
\hline$c_{30}=1,90204$ & $c_{31}=-1,23850$ & $c_{32}=0,447985$ & $c_{33}=0,001871$ \\
\hline
\end{tabular}

(19) - (22) is in the form:

$x(s, t)=0,207035 \sin (s)+1,94309 \cdot 10^{5} \sin (2 s)-1,33263 \cdot 10^{7} \sin (3 s)-$ $-3,94892 \cdot 10^{-9} \sin (s) t^{9}-7,12624 \cdot 10^{-9} \sin (3 s) t^{9}-1,9430810^{5} e^{-\frac{1}{3} t} \sin (2 s)+$ $+1,16963 \cdot 10^{-8} \sin (2 s) t^{9}+1,33263 \cdot 10^{7} e^{-\frac{1}{8} t} \sin (3 s)+1,66578 \cdot 10^{6} \sin (3 s) t-$ $-1,04111 \cdot 10^{5} \sin (3 s) t^{2}+0,002711 \sin (2 s) t^{7}+0,000011 \sin (2 s) t^{8}+$ $+4337,61 \sin (3 s) t^{3}-135,521 \sin (3 s) t^{4}+3,30193 \sin (3 s) t^{5}-0,049447 \sin (3 s) t^{6}-$ $-0,000959 \sin (3 s) t^{7}-0,000005 \sin (3 s) t^{8}+0,198778 \sin (2 s) t^{6}-$

$-5,92736 \sin (2 s) t^{5}-64768,6 \sin (2 s) t+96,5275 \sin (2 s) t^{4}-$ $-1195,08 \sin (2 s) t^{3}+10792,9 \sin (2 s) t^{2}+0,089563 \sin (s) t-$ $-0,000003 \sin (s) t^{8}-0,000553 \sin (s) t^{7}+, 292602 \sin (s) t^{5}-$ $-0,035173 \sin (s) t^{6}-0,871872 \sin (s) t^{4}+1,05038 \sin (s) t^{3}-0,499923 \sin (s) t^{2}$, $v(s, t)=0,576594 e-3 \sin (s) t^{3}+0,0410941 \sin (s) t^{2}-$ $-0,0164711 \sin (s) t+0,185899 \sin (s)-0,000372 \sin (2 s) t^{3}-$ $-0,187661 \sin (2 s) t^{2}+0,622777 \sin (2 s) t+0,750882 \sin (2 s)+$ $+0,001493 \sin (3 s) t^{3}+0,357441 \sin (3 s) t^{2}-0,988178 \sin (3 s) t+1,51761 \sin (3 s)$, 


$$
\begin{aligned}
& u(s, t)=0,011642 \sin (s) t^{3}+0,265256 \sin (s) t^{2}+0,152685 \sin (s) t+ \\
& +3,02040 \sin (s)-8,40566 \sin (2 s) t^{3}+10,7541 \sin (2 s) t^{2}-4,52191 \sin (2 s) t+ \\
& +7,61814 \sin (2 s)-5,75434 \sin (3 s) t^{3}+0,895680 \sin (3 s) t^{2}+5,20241 \sin (3 s) t- \\
& -0,099820 \sin (3 s) .
\end{aligned}
$$

The graphs of an approximate solution of problem (19) - (22) are presented in Fig. 2 and Fig. 3. The graphs of the functions $x(s, 1), v(s, 1), z_{d}(s, 1)$, when $t=1$, are presented in Fig. 4.

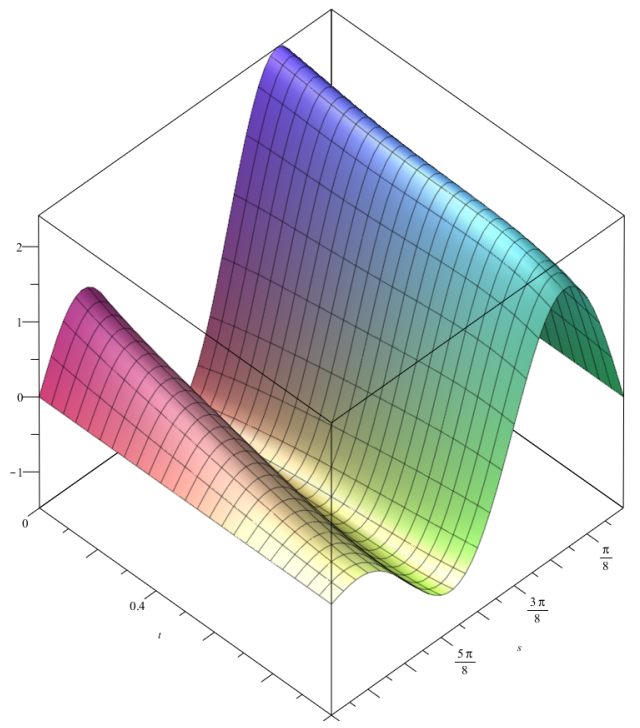

a)

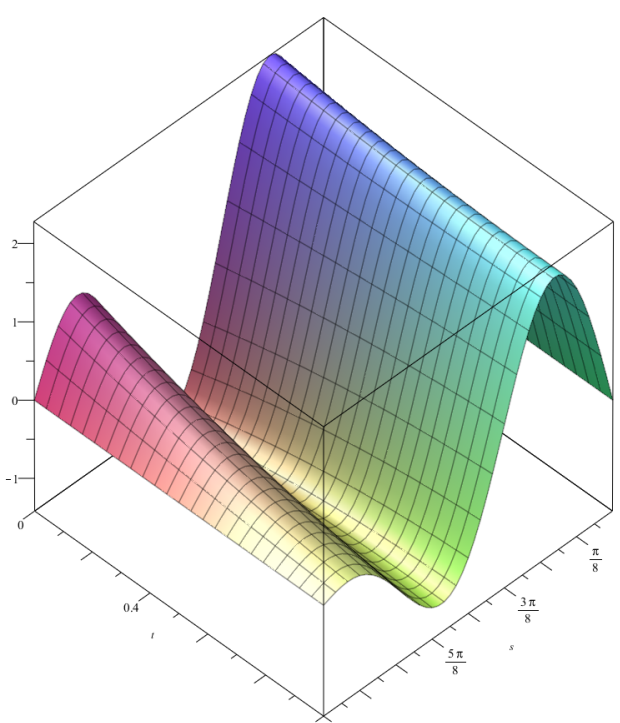

b)

Fig. 2. The graph of the numerical solution of problem (19) - (22):

a) function $x(s, t)$; b) function $v(s, t)$

We are interested in the process of the control of a behavior of the construction of I-beams under a constant load. Consider finite connected directed graph $\mathbf{G}=\mathbf{G}(\mathcal{V} ; \mathcal{E})$, where $\mathcal{V}=\left\{V_{i}\right\}_{i=1}^{N}$ is a set of the vertices, and $\mathcal{E}=\left\{E_{j}\right\}_{j=1}^{N}$ is a set of the arcs. We assume that each arc has a length $l_{j}>0$ and the cross sectional area of an edge $d_{j}>0$. On a graph $\mathbf{G}$ we consider the equation

$$
\begin{gathered}
-\lambda x_{j t}-x_{j t s s}+\alpha_{j}^{1} x_{j}+\alpha_{j}^{2} x_{j}^{3}+\ldots+\alpha_{j}^{k} x_{j}^{2 k+1}=u_{j}, \\
\text { для всех } s \in\left(0, l_{j}\right), t \in \mathbb{R}, j=1, N .
\end{gathered}
$$

For equations (26) at each vertex $V_{i}, i=\overline{1, M}$ we define the boundary conditions

$$
\begin{gathered}
\sum_{j: E_{j} \in E^{\alpha}\left(V_{i}\right)} d_{j} x_{j s}(0, t)-\sum_{r: E_{r} \in E^{\omega}\left(V_{i}\right)} d_{r} x_{r s}\left(l_{r}, t\right)=0 \\
u_{r}(0, t)=u_{j}(0, t)=u_{h}\left(l_{h}, t\right)=u_{m}\left(l_{m}, t\right)
\end{gathered}
$$

for all $E_{r}, E_{j} \in E^{\alpha}\left(V_{i}\right), E_{h}, E_{m} \in E^{\omega}\left(V_{i}\right)$. Here $E^{\alpha(\omega)}\left(V_{i}\right)$ is a set of the arcs with the end at a vertex $V_{i}$. 


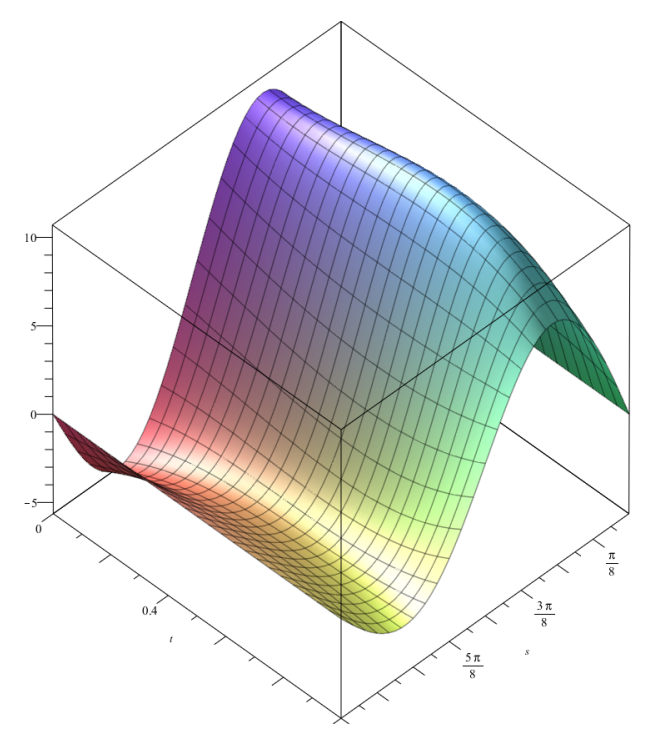

Fig. 3. The graph of an optimal control $u(s, t)$ by solutions of problem (19) - (22)

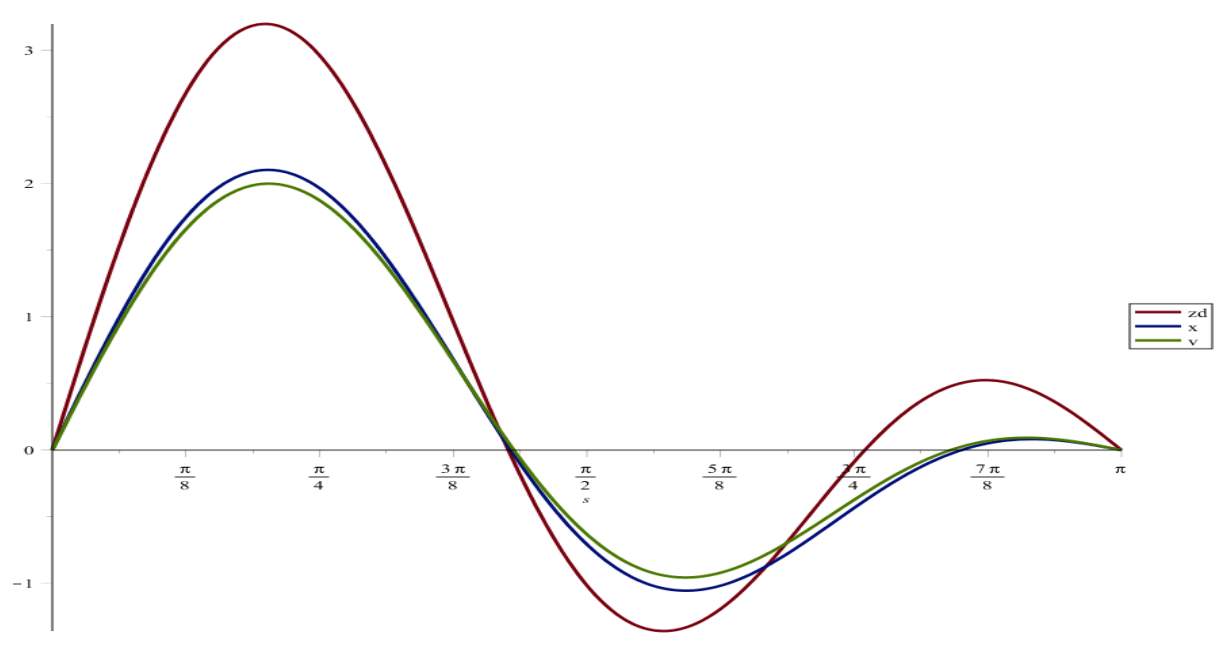

Fig. 4. The graph of the numerical solution of problem (19) - (22) at the time moment $t=1$

Let us add the initial Showalter - Sidorov conditions

$$
(\lambda+\Delta)\left(x_{j}(s, 0)-x_{0 j}(s)\right)=0, \text { для всех } s \in\left(0, l_{j}\right),
$$

to (27), (28). So we get the Showalter - Sidorov - Neumann problem for equations (26). Our goal is to find an approximate solution of the optimal control problem

$$
J(x, u) \rightarrow \min
$$


by the solutions of problem (26) - (30), where the cost functional is in the form

$$
\begin{aligned}
& J(x, u)=\sum_{E_{j} \in \mathrm{E}} \beta \int_{0}^{T} d_{j} \int_{0}^{l_{j}}\left|x_{j}(s, t)-z_{j d}(s, t)\right|^{2 k+2} d s d t+ \\
& +(1-\beta) \sum_{E_{j} \in \mathrm{E}} \int_{0}^{T} \int_{0}^{l_{j}} d_{j}\left|u_{j}\right|^{2} d s d t .
\end{aligned}
$$

The algorithm for finding an approximate solution of problem (26) - (30) using decomposition, penalty, Galerkin - Petrov methods was described in 2. By the proposed method on the graph $\mathbf{G}$ consider the equations

$$
-\lambda x_{j t}-x_{j t s s}+\alpha_{j} x_{j}+\alpha_{j}^{1} v_{j}^{3}+\ldots+\alpha_{j}^{k} v_{j}^{2 k+1}=u_{j} .
$$

Equations (32) are linear with respect to the functions $x_{j}(s, t)$. We define a penalty functional in the form

$$
\begin{aligned}
& J_{\theta}^{\varepsilon}(x, v, u)=\sum_{E_{j} \in \mathrm{E}} \beta \theta \int_{0}^{T} d_{j} \int_{0}^{l_{j}}\left|x_{j}(s, t)-z_{j d}(s, t)\right|^{2 k+2} d s d t+ \\
& +\sum_{E_{j} \in \mathrm{E}} \beta(1-\theta) \int_{0}^{T} d_{j} \int_{0}^{l_{j}}\left|v_{j}(s, t)-z_{j d}(s, t)\right|^{2 k+2} d s d t+ \\
& +(1-\beta) \sum_{E_{j} \in \mathrm{E}} \int_{0}^{T} \int_{0}^{l_{j}} d_{j}\left|u_{j}\right|^{2} d s d t+ \\
& +\sum_{E_{j} \in \mathrm{E}} \frac{1}{\varepsilon} \int_{0}^{T} d_{j} \int_{0}^{l_{j}}\left|x_{j}(s, t)-v_{j}(s, t)\right|^{2} d s d t
\end{aligned}
$$

Example 2. It is required to find the approximate solution of problem (26) - (30) on the oriented graph $\mathbf{G}$, which consists of two serially connected edges and three vertices. Here $k=1, \lambda=0, \alpha_{1}=\alpha_{2}=1, \beta=\theta=\frac{1}{2}, \varepsilon=\frac{1}{10}, d_{1}=1, d_{2}=1, l_{1}=\pi, l_{2}=\pi, N=2$ and the initial functions (see Fig. 5) are

$$
\begin{gathered}
x_{01}(s)=0.225676 \cos s, x_{02}(s)=-0.225676 \cos s \\
z_{1 d}(s)=\left(0.225676\left(t^{2}+1\right)\right) \cos s, z_{2 d}(s)=-\left(0.225676\left(t^{2}+1\right)\right) \cos s .
\end{gathered}
$$

The results of the calculations are the coefficients of the control (see. Table 2) such that the value of the functional $J=0,758280$. An approximate solution of problem (26) - (30) is in the form:

$$
\begin{aligned}
& x_{1}(s, t)=-0,000269+0,000858 t-0,035642 t^{2}+0,016320 t^{9}-0,085926 t^{8}- \\
& -0,327578 t^{6}+0,203202 t^{7}+0,415751 t^{5}-0,364575 t^{4}+0,177582 t^{3}- \\
& -0,000022 e^{-4 t}\left(-57885,8 e^{4 t} t^{7}+15705,2 e^{4 t} t^{8}-2048,73 e^{4 t} t^{9}-\right. \\
& -2,53678 \cdot 10^{5} e^{4 t} t^{5}-3,62799 \cdot 10^{5} e^{4 t} t^{3}+2,66670 \cdot 10^{5} e^{4 t} t^{2}- \\
& -1,39073 \cdot 10^{5} e^{4 t} t+3,53474 \cdot 10^{5} e^{4 t} t^{4}+1,40785 \cdot 10^{5} e^{4 t} t^{6}+38532,2 e^{4 t}- \\
& -38532,3) \cos (0,5 s)+0,564191 e^{-t}\left(39958,5-39957,8 e^{t}+39958,0 e^{t} t+\right. \\
& +332,582 e^{t} t^{5}-55,1402 e^{t} t^{6}+6659,28 e^{t} t^{3}-1664,61 e^{t} t^{4}-19978,8 e^{t} t^{2}+ \\
& \left.+7,69238 e^{t} t^{7}-0,866750 e^{t} t^{8}+0,611560 e-e^{t} t^{9}\right) \cos (s)
\end{aligned}
$$




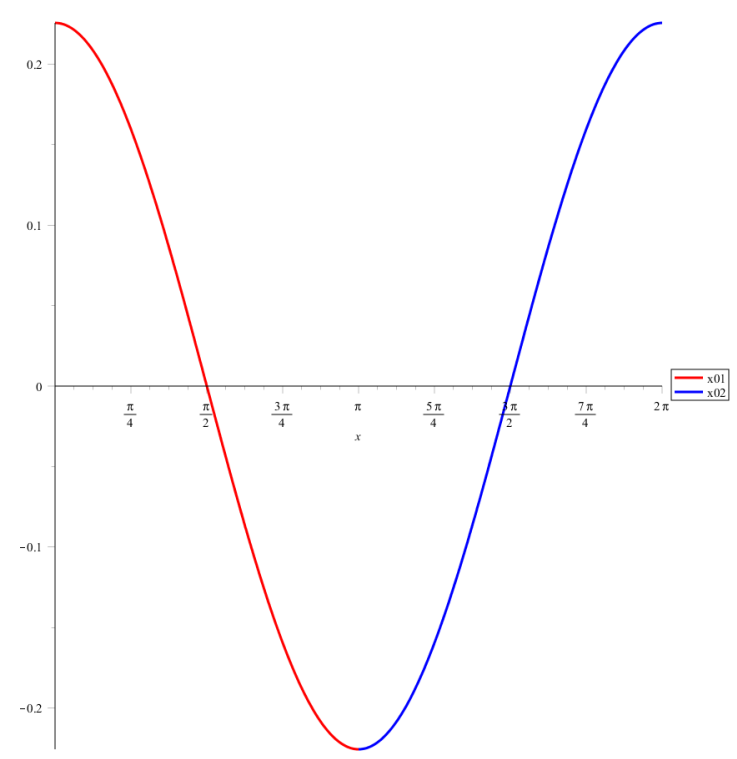

Fig. 5. The initial deflection $x_{01}, x_{02}$

Table 2

\begin{tabular}{|l|l|l|l|}
\hline$b_{00}=-0,000898$ & $b_{01}=0,000519$ & $b_{02}=0,004183$ & $b_{03}=-0,004247$ \\
\hline$b_{10}=-0,150189$ & $b_{11}=-0,009871$ & $b_{12}=1,003754$ & $b_{13}=-0,804374$ \\
\hline$b_{20}=0,664529$ & $b_{21}=0,074235$ & $b_{22}=-0,374667$ & $b_{23}=-0,360942$ \\
\hline$c_{00}=-0,000514$ & $c_{01}=-0,009678$ & $c_{02}=0,028825$ & $c_{03}=-0,019824$ \\
\hline$c_{10}=-0,008221$ & $c_{11}=-0,495853$ & $c_{12}=1,146591$ & $c_{13}=-0,595256$ \\
\hline$c_{20}=1,000790$ & $c_{21}=-0,522917$ & $c_{22}=0,438774$ & $c_{23}=-0,306497$ \\
\hline
\end{tabular}

$x_{2}(s, t)=-0,000269-3+0,00086 t-0,0356416 t^{2}+0,016320 t^{9}-0,085925 t^{8}-$ $-0,327578 t^{6}+0,203202 t^{7}+0,415751 t^{5}-0,364575 t^{4}+0,177582 t^{3}+$ $+0,000022 e^{-4 t}\left(-57885,8 e^{4 t} t^{7}+15705,2 e^{4 t} t^{8}-2048,73 e^{4 t} t^{9}-2,53678 \cdot 10^{5} e^{4 t} t^{5}-\right.$ $-3,62799 \cdot 10^{5} e^{4 t} t^{3}+2,66670 \cdot 10^{5} e^{4 t} t^{2}-1,39073 \cdot 10^{5} e^{4 t} t+3,53474 \cdot 10^{5} e^{4 t} t^{4}+$ $\left.+1,40785 \cdot 10^{5} e^{4 t} t^{6}+38532,2 e^{4 t}-38532,3\right) \sin (0,5 s)-0,564191 e^{-t}(39958,5-$ $-39957,8 e^{t}+39958,0 e^{t} t+332,582 e^{t} t^{5}-55,1402 e^{t} t^{6}+6659,28 e^{t} t^{3}-$ $-1664,61 e^{t} t^{4}-19978,8 e^{t} t^{2}+7,69238 e^{t} t^{7}-$ $\left.-0,866750 e^{t} t^{8}+0,061156 e^{t} t^{9}\right) \cos (s)$,

$v_{1}(s, t)=-0,007908 t^{3}+0,011499 t^{2}-0,003861 t-0,000204+$ $\left.+0,564191\left(-0,595256 t^{3}+1,14659 t^{2}-0,495853 t-0,008221\right)\right) \cos (0,5 s)+$ $\left.+0,564191\left(-0,306497 t^{3}+, 438774 t^{2}-0,522917 t+1,00079\right)\right) \cos (s)$,

$v_{2}(s, t)=-0,007908 t^{3}+0,011499 t^{2}-0,003861 t-0,000204-$ $\left.-0,564191\left(-0,595256 t^{3}+1,14659 t^{2}-0,495853 t-0,008221\right)\right) \sin (0,5 s)-$ $\left.-0,564191\left(-0,306497 t^{3}+, 438774 t^{2}-0,522917 t+1,00079\right)\right) \cos (s)$,

$u_{1}(s, t)=-0,001694 t^{3}+0,001668 t^{2}+0,000207 t-0,000358+$ $\left.+0,564191\left(-0,804374 t^{3}+1,00375 t^{2}-0,009870 t-0,150189\right)\right) \cos (0,5 s)+$ $\left.+0,564191\left(-0,360942 t^{3}-0,374667 t^{2}+0,0742352 t+0,664529\right)\right) \cos (s)$, 


$$
\begin{aligned}
& u_{2}(s, t)=-0,001694 t^{3}+0,001668 t^{2}+0,000207 t-0,000358- \\
& \left.-0,564191\left(-0,804374 t^{3}+1,00375 t^{2}-0,009870 t-0,150189\right)\right) \sin (0,5 s)- \\
& \left.-0,564191\left(-0,360942 t^{3}-0,374667 t^{2}+0,0742352 t+0,664529\right)\right) \cos (s) .
\end{aligned}
$$

The graphs of an approximate solution of problem (26) - (30) are presented in Fig. 6 and Fig. 7.

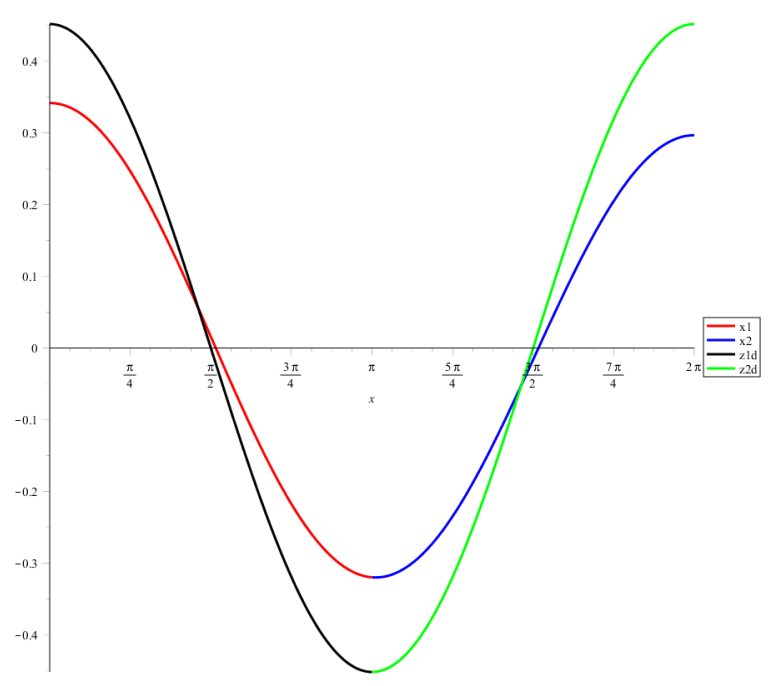

a)

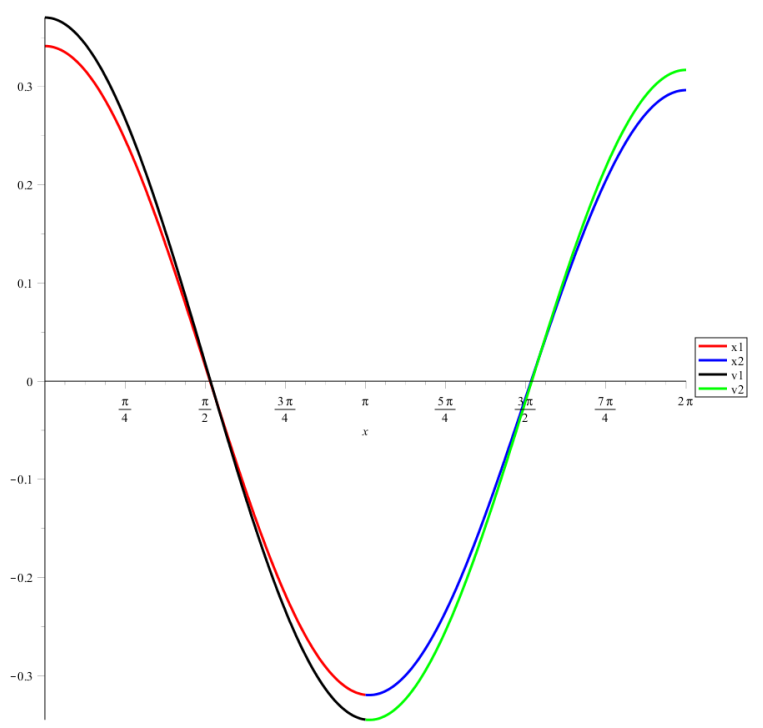

b)

Fig. 6. The graph of numerical solution of problem $(26)-(30)$ :

a) function $x_{1}(s, 1), x_{2}(s, 1), z_{d 1}(s, 1), z_{d 2}(s, 1)$; b) function $x_{1}(s, 1), x_{2}(s, 1), v_{1}(s, 1), v_{2}(s, 1)$

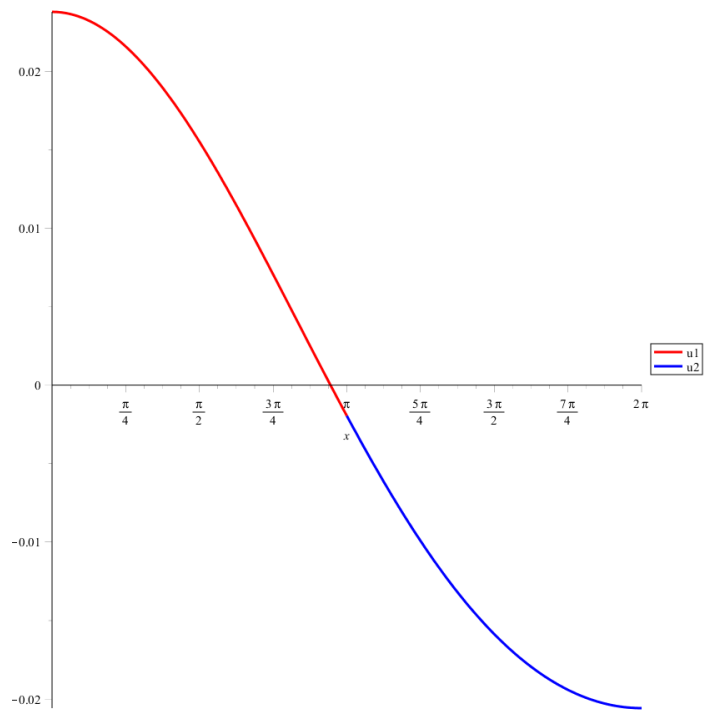

Fig. 7. The control $u_{1}(s, 1), u_{2}(s, 1)$ 


\section{References}

1. Sidorov N., Loginov B., Sinithyn A., Falaleev M. Lyapunov - Shmidt Methods in Nonlinear Analysis and Applications. Dordrecht, Boston, London, Kluwer Academic Publishers, 2002. 548 p.

2. Sviridyuk G.A., Fedorov V.E. Linear Sobolev Type Equations and Degenerate Semigroups of Operators. Utrecht, Boston, Köln, VSP, 2003. 216 p.

3. Demidenko G.V., Uspenskii S.V. Partial Differential Equations and Systems not Solvable with Respect to the Highest Order Derivative. N.Y., Basel, Hong Kong, Marcel Dekker, Inc., 2003.

4. Al'shin A.B., Korpusov M.O., Sveshnikov A.G. Blow-up in Nonlinear Sobolev Type Equations. Series in Nonlinear Analisys and Applications, 15, De Gruyter, 2011. DOI: $10.1515 / 9783110255294$

5. Zamyshlyaeva A.A. Linear Sobolev Type Equations of High Order. Chelyabinsk, Publ. Center of the SUSU, 2012. (in Russian)

6. Sagadeeva M.A. Dichotomy of Solutions of Linear Sobolev Type Equations. Chelyabinsk, Publ. Center of the SUSU, 2012. (in Russian)

7. Showalter R.E. The Sobolev Equation. Applicable Analysis, 1975, vol. 5, no. 1, pp. 1522; vol. 5, no. 2, pp. 81-89.

8. Sviridyuk G.A., Efremov A.A. Optimal Control of Sobolev Type Linear Equations with Relativity p-Sectorial Operators. Differential Equations, 1995, vol. 31, no. 11, pp. 1882-1890.

9. Manakova N.A., Dyl'kov A.G. Optimal Control of the Solutions of the InitialFinish Problem for the Linear Hoff Model. Mathematical Notes, 2013, vol. 94, no. 2, pp. 220-230.

10. Zamyshlyaeva A.A., Tsyplenkova O.N. Optimal Control of Solutions of the Showalter - Sidorov - Dirichlet Problem for the Boussinesq - Love Equation. Differential Equations, 2013, vol. 49, no. 11, pp. 1356-1365. DOI: 10.1134/S0012266113110049

11. Keller A.V. Numerical Solution of the Optimal Control Problem for Degenerate Linear System of Equations with Showalter - Sidorov Initial Conditions. Bulletin of the South Ural State University. Series: Mathematical Modelling, Programming and Computer Software, 2008, no. 27 (127), issue 2, pp. 50-56. (in Russian)

12. Keller A.V., Sagadeeva M.A. [The Numerical Solution of Optimal and Hard Control for Nonstationary System of Leontiev Type]. Belgorod State University Scientific Bulletin. Mathematics, Physics, 2013, vol. 32, no. 19, pp. 57-66. (in Russian)

13. Shestakov A.L., Sviridyuk G.A. Optimal Measurement of Dynamically Distorted Signals. Bulletin of the South Ural State University. Series: Mathematical Modelling, Programming and Computer Software, 2011, no. 17 (234), issue 8, pp. 70-75. (in Russian)

14. Shestakov A.L., Keller A.V., Nazarova E.I. Numerical Solution of the Optimal Measurement Problem. Automation and Remote Control, 2012, vol. 73, no. 1, pp. 97-104. DOI: 10.1134/S0005117912010079 
15. Sviridyuk G.A., Zagrebina S.A. The Showalter - Sidorov Problem as a Phenomena of the Sobolev-Type Equations. The Bulletin of Irkutsk State University. Series: Mathematics, 2010, vol. 3, no. 1, pp. 104-125. (in Russian)

16. Zagrebina S.A. The Initial-Finite Problems for Nonclassical Models of Mathematical Physics. Bulletin of the South Ural State University. Series: Mathematical Modelling, Programming and Computer Software, 2013, vol. 6, no. 2, pp. 5-24. (in Russian)

17. Lions J.-L. Contrôle optimal de systémes gouvernés par des équations aux dérivées partielles. Paris, Dunod, 1968.

18. Sviridyuk G.A., Manakova N.A. An Optimal Control Problem for the Hoff Equation. Journal of Applied and Industrial Mathematics, 2007, vol. 1, no. 2, pp. 247-253.

19. Manakova N.A. An Optimal Control to Solutions of the Showalter - Sidorov Problem for the Hoff Model of the Geometrical Graph. Journal of Computational and Engineering Mathematics, 2014, vol. 1, no. 1, pp. 26-33.

20. Sviridyuk G.A. A Problem for the Generalized Boussinesq Filtration Equation. Soviet Mathematics (Izvestiya VUZ. Matematika), 1989, vol. 33, no. 2, pp. 62-73.

21. Manakova N.A. Method of Decomposition in the Optimal Control Problem for Semilinear Sobolev Type Models. Bulletin of the South Ural State University. Series: Mathematical Modelling, Programming and Computer Software, 2015, vol. 8, no. 2, pp. 133-137. (in Russian)

Natalia A. Manakova, candidate of physical and mathematical sciences, associate professor, department of equation of mathematical physics, South Ural State University, Chelyabinsk, Russian Federation, manakovana@susu.ac.ru.

Received September 14, 2015

УДК 517.9

DOI: $10.14529 /$ jcem150305

\section{АЛГОРИТМ ЧИСЛЕННОГО МЕТОДА РЕШЕНИЯ ЗАДАЧИ ОПТИМАЛЬНОГО УПРАВЛЕНИЯ ДЛЯ ПОЛУЛИНЕЙНЫХ МОДЕЛЕЙ СОБОЛЕВСКОГО ТИПА НА ОСНОВЕ МЕТОДА ДЕКОМПОЗИЦИИ}

\section{Н.А. Манакова}

В связи с большим количеством приложений на первый план выходит вопрос о нахождении численного решения задач оптимального управления в математических моделях на основе вырожденных полулинейных уравнений математической физики. 
В случае нелинейного уравнения состояния поиск численного решения задачи оптимального управления значительно затрудняется. Обширный класс начально-краевых задач для уравнений и систем уравнений в частных производных не разрешенных относительно производной по времени могут быть изучены в рамках теории уравнений соболевского типа. Нас интересует исследование задачи оптимального управления для полулинейного уравнения соболевского типа. В статье предложено использовать метод декомпозиции, позволяющий линеаризовать нелинейное уравнение, и метод штрафа, позволяющий находить приближенное решение поставленной задачи. На основе метода Галеркина и метода декомпозиции построен численный метод, при помощи которого находятся приближенные решения задачи оптимального управления для математической модели Хоффа и обобщенной математической модели деформации конструкции из двутавровых балок.

Ключевые слова: уравнения соболевского типа; оптимальное управление; задача Шоуолтера - Сидорова; метод Галеркина; метод декомпозичии.

\section{Литература}

1. Sidorov, N. Lyapunov - Shmidt Methods in Nonlinear Analysis and Applications / N. Sidorov, B. Loginov, A. Sinithsyn, M. Falaleev. - Dordrecht; Boston; London: Kluwer Academic Publishers, 2002. - 548 p.

2. Sviridyuk, G.A. Linear Sobolev Type Equations and Degenerate Semigroups of Operators / G.A. Sviridyuk, V.E. Fedorov. - Utrecht; Boston; Köln: VSP, 2003. 216 p.

3. Demidenko, G.V. $L_{p}$-Theory of Boundary Value Problems for Sobolev Type Equaitons / G.V. Demidenko // Partial Differential Equations (Banach Center Publications). 1992. - V. 27. - P. 101-109.

4. Линейные и нелинейные уравнения соболевского типа / А.Г. Свешников, А.Б. Альшин, М.О. Корпусов, Ю.Д. Плетнер. - М.: ФИЗМАТЛИТ, 2007. - 736 с.

5. Замышляева, А.А. Линейные уравнения соболевского типа высокого порядка / А.А. Замышляева. - Челябинск: Изд. центр ЮУрГУ, 2012. - 107 с.

6. Сагадеева, М.А. Дихотомии решений линейных уравнений соболевского типа / М.А. Сагадеева. - Челябинск: Изд. центр ЮУрГУ, 2012. - 107 с.

7. Showalter, R.E. The Sobolev Equation / R.E. Showalter // Applicable Analysis. 1975. - V. 5, № 1. - P. 15-22; V. 5, № 2. - P. 81-89.

8. Свиридюк, Г.А. Оптимальное управление линейными уравнениями типа Соболева с относительно р-секториальными операторами / Г.А. Свиридюк, А.А. Ефремов // Дифференциальные уравнения. - 1995. - Т. 31, № 11. - С. 1912-1919.

9. Манакова, Н.А. Оптимальное управление решениями начально-конечной задачи для линейной модели Хоффа / Н.А. Манакова, А.Г. Дыльков // Математические заметки. - 2013. - Т. 94, № 2. - С. 225-236.

10. Замышляева, А.А. Оптимальное управление решениями задачи Шоуолтера Сидорова - Дирихле для уравнения Буссинеска - Лява / А.А. Замышляева, О.Н. Цыпленкова // Дифференциальные уравнения. - 2013. - Т. 49, № 11. C. $1390-1398$. 
11. Келлер, А.В. Численное решение задачи оптимального управления вырожденной линейной системой уравнений с начальными условиями Шоуолтера - Сидорова / А.В. Келлер // Вестник ЮУрГУ. Серия: Математическое моделирование и программирование. - 2008. - № 27 (127), вып. 2. - С. 50-56.

12. Келлер, А.В. Численное решение задач оптимального и жесткого управления для одной нестационарной системы леонтьевского типа / А.В. Келлер, М.А. Сагадеева // Научные ведомости Белгородского государственного университета. Серия: Математика. Физика. - 2013. - Т. 32, № 19. - С. 57-66.

13. Шестаков, А.Л. Оптимальное измерение динамически искаженных сигналов А.Л. Шестаков, Г.А. Свиридюк // Вестник ЮУрГУ. Серия: Математическое моделирование и программирование. - 2011. - № 17 (234), вып. 8. - С. 70-75.

14. Шестаков, А.Л. Численное решение задачи оптимального измерения / А.Л. Шестаков, А.В. Келлер, Е.И. Назарова // Автоматика и телемеханика. - 2012. - № 1. - C. $107-115$.

15. Свиридюк, Г.А. Задача Шоуолтера - Сидорова как феномен уравнений соболевского типа / Г.А. Свиридюк, С.А. Загребина // Известия Иркутского государственного университета. Серия: Математика. - 2010. - Т. 3, № 1. - С. 51-72.

16. Загребина, С.А. Начально-конечные задачи для неклассических моделей математической физики / С.А. Загребина // Вестник ЮУрГУ. Серия: Математическое моделирование и программирование. - 2013. - Т. 6, № 2. - С. 5-24.

17. Лионс, Ж.-Л. Управление сингулярными распределенными системами Ж.-Л. Лионс. - М.: Наука, 1987. - 367 с.

18. Свиридюк, Г.А. Задача оптимального управления для уравнения Хоффа / Г.А. Свиридюк, Н.А. Манакова // Сибирский журнал индустриальной математики. - 2005. - Т. 8, № 2. - С. 144-151.

19. Manakova, N.A. An Optimal Control to Solutions of the Showalter - Sidorov Problem for the Hoff Model of the Geometrical Graph // Journal of Computational and Engineering Mathematics. - 2014. - V. 1, № 1. - P. 26-33.

20. Свиридюк, Г.А. Одна задача для обобщенного фильтрационного уравнения Буссинеска / Г.А. Свиридюк // Известия вузов. Математика. - 1989. - Т. 33, № 2. C. $62-73$.

21. Манакова, Н.А. Метод декомпозиции в задаче оптимального управления для полулинейных моделей соболевского типа / Н.А. Манакова // Вестник ЮУрГУ. Серия: Математическое моделирование и программирование. - 2015. - Т. 8, № 2. - C. 133-137.

Манакова Наталвя Александровна, кандидат физико-математических наук, доцент, кафедра уравнений математической физики, Южно-Уральский государственный университет (г. Челябинск, Российская Федерация), manakovana@susu.ac.ru.

Поступила в редакиию 14 сентября 2015 г. 